\title{
Application of PCA in Psychological Health and Assistance Program of Middle School Student
}

\author{
Feihua Qu \\ Handan NO. 2 High School, Handan, Hebei Province, 056106 China \\ chinaqfh@163.com
}

Keywords: PCA; Middle school student; Psychological health and assistance; Mathematical model

\begin{abstract}
The ideas of psychological health and assistance program of middle school student, its services, benefits are introduced. At the same time, the authors tell what the primary components analysis (PCA) is and the advantages it has. On the basis of PCA model and the scores by the experts, the authors compute some results which can reflect some aspects about the problem investigation. Through using PCA to analyze psychological health and assistance, it can be seen that some problems play very important role in the analysis of problem happening with PCA, and all the problems which affect employee should be taken into account because psychological knowledge propaganda, psychological education curriculum, psychological counseling, growth relay plan, creating the communication platform between college students and middle school students, et al, depends on the combination of a wide range of problems solution.
\end{abstract}

\section{Introduction}

The core of mental health is to aid and care middle school students in all-round and various mental health assistance and services, which is to create students' sunshine state of mind, a healthy soul, and to achieve the perfect life. The main activities, also the main indexes, are as follow [1-5].

(1) Propaganda psychological knowledge. Through freely distributing the mental health pamphlet publications, making the psychological publicity boards, carrying out the mental health propaganda lectures, psychological investigation and tests and so on, the psychological knowledge and the common psychological solutions are popularized.

(2) Psychological curriculum teaching. With the school negotiation in the form of teach volunteering, a regular organization of psychology college students is carried out to educate psychological curriculum in middle school, and the group training, situational experience and other forms of conversation are launched.

(3) To help the secondary school set up psychological counseling rooms. The psychology college students are on duty in regular psychological counseling room. And the high school student psychological profile should be set up, which pays more attentions to each student, especially the students of poor psychological quality.

(4) Relay growth plan. A platform for college students and middle school students should be created. Through the guidance of learning experience, life experience, schooling, the University future and the professional selection and other aspects by the college students to the middle school students, the road to learn the experience is of inheritance in order to promote the better growth of middle school students.

(5) Fast reading and shorthand training. Through the fast reading and the rapid memory training, the students learning ability and efficiency have been greatly improved and the learning pressure should be eased.

(6) Founding the psychology editor office. By editing magazines, newspapers and pamphlets, the office should become a position to promoting psychological knowledge and advertising financing channels.

(7) Organizing the education volunteering activities of mental health to the child in impoverished mountainous area in summer. 


\section{Procedures of PCA}

Principal component analysis is that the original number of $\mathrm{p}$ correlative indexes is recombined into a new set of independent comprehensive indexes to replace the original. These indicators can also reflect the original index information, which can objectively determine the weight of each index in order to avoid the subjectivity of the influence of human intervention. Principal component analysis (PCA) is characterized by a linear transformation between principal components which are mutually independent, and can eliminate the influence of the original index between relative. A lot of repetitive work is reduced while selecting indicators. But for other methods, the effect of relative index cannot be eliminated, thus, it will waste a lot of time in the index selection. In contrast, the principal component analysis (PCA) is easy to use in the process of calculation and application. The principal components can be sorted according to the variance of the analysis process. In dealing with the practical problems, we can choose the main component of the larger variance rather than other components, so that the calculation workload can be reduced [6-8].

It is assumed that there are $\mathrm{n}$ samples, each of which observes $X_{1}, X_{2}, \cdots, X_{p}$, then the primitive data can be changed as follow.

$$
X=\left[\begin{array}{cccc}
x_{11} & x_{12} & \cdots & x_{1 p} \\
x_{21} & x_{22} & \cdots & x_{2 p} \\
\vdots & \vdots & & \vdots \\
x_{n 1} & x_{n 2} & \cdots & x_{n p}
\end{array}\right]
$$

Step 1 Standardizing the data

Step 2 Setting up the relative coefficients of $\mathrm{X}, R=\left(r_{i j}\right)_{p \times p}$. Where

$$
r_{i j}=\frac{\sum_{a=1}^{n}\left(x_{a i}-\bar{x}_{i}\right)\left(x_{a j}-\bar{x}_{j}\right)}{\sqrt{\sum_{a=1}^{n}\left(x_{a i}-\bar{x}_{i}\right)^{2}} \cdot \sqrt{\sum_{a=1}^{n}\left(x_{a j}-\bar{x}_{j}\right)^{2}}}=\frac{1}{n} \sum_{a=1}^{n} x_{a i} \bullet x_{a j}
$$

Step 3 Calculating the characteristic vectors $\mathrm{u}$ and characteristic roots of $R$ and ascertain the primary component. According to the related coefficient matrix, $p$ characteristic roots are determined which is not less than $0, \lambda_{1} \geq \lambda_{2} \geq \cdots \geq \lambda_{p}>0$. Each characteristic roots is related to $u_{1}, u_{2}, \cdots, u_{p}$.

$$
U=\left(u_{1}, u_{2}, \cdots, u_{p}\right)=\left[\begin{array}{cccc}
u_{11} & u_{12} & \cdots & u_{1 p} \\
u_{21} & u_{22} & \cdots & u_{2 p} \\
\vdots & \vdots & & \vdots \\
u_{p 1} & u_{p 2} & \cdots & u_{p p}
\end{array}\right]
$$

Step 4 The variance contribution rate is computed and the number of primary component are settled. The accumulative total contribution rate of the anterior $p$ primary component is calculated. If the accumulative total contribution rate is not less than $90 \%$, the $p$ primary components are reserved as the primary. Thus, the amount of synthetics indexes $\mathrm{F}$ can be reduced to $p$ and the filtration is realized.

$$
F_{i}=a_{1 i} X_{1}+a_{2 i} X_{2}+\cdots+a_{p i} X_{p} \quad i=1,2, \cdots, p
$$




\section{Analysis of Psychological Health and Assistance Program of Middle School Student}

The scope of psychological health and assistance program of middle school student include seven aspects, which is expressed as variable xi $(\mathrm{i}=1,2, \ldots, 7)$ such as (x1) propaganda psychological knowledge, (x2) psychological curriculum teaching, (x3) helping the secondary school set up psychological counseling rooms, (x4) relay growth plan, (x5) fast reading and shorthand training, (x6) founding the psychology editor office and (x7) organizing the education volunteering activities of mental health to the child in impoverished mountainous area.

Using the mathematical model given above, the solution s of psychological health and assistance program of middle school student are analyzed and evaluated. As the seven aspects above, according to the effects and importance, some experts of psychological health and assistance can score. The maximum score of each item is 10 . The primitive data by experts are shown in table 1 .

Table 1 Score by experts

\begin{tabular}{|c|c|c|c|c|c|c|c|}
\hline ID & $x_{1}$ & $x_{2}$ & $x_{3}$ & $x_{4}$ & $x_{5}$ & $x_{6}$ & $x_{7}$ \\
\hline 1 & 9.1 & 8.8 & 9.2 & 9.3 & 9.9 & 9.8 & 9.2 \\
\hline 2 & 9.5 & 9.1 & 9.1 & 9.2 & 9.6 & 9.3 & 9.5 \\
\hline 3 & 9.5 & 9.7 & 9.1 & 9.4 & 9.6 & 9.6 & 9.3 \\
\hline 4 & 9.2 & 9.4 & 9.5 & 9.2 & 9.1 & 9 & 9.6 \\
\hline 5 & 9.5 & 9.1 & 9.2 & 9.2 & 9.5 & 9.4 & 9.6 \\
\hline 6 & 9.5 & 9 & 9 & 9 & 9.5 & 9.6 & 9.1 \\
\hline 7 & 9.5 & 9.7 & 9.2 & 9.4 & 9.5 & 9.2 & 9.5 \\
\hline
\end{tabular}

Data Standardization

Table 2 Data after standardizing

\begin{tabular}{cccccccc}
\hline ID & $\boldsymbol{x}_{\mathbf{1}}$ & $\boldsymbol{x}_{\mathbf{2}}$ & $\boldsymbol{x}_{\mathbf{3}}$ & $\boldsymbol{x}_{\mathbf{4}}$ & $\boldsymbol{x}_{\mathbf{5}}$ & $\boldsymbol{x}_{\mathbf{6}}$ & $\boldsymbol{x}_{\mathbf{7}}$ \\
\hline 1 & -1.8708 & -1.4708 & 0.0981 & 0.4417 & 1.6997 & 1.5237 & -1.0801 \\
2 & 0.6236 & -0.4842 & -0.5883 & -0.3313 & 0.3269 & -0.4515 & 0.5401 \\
3 & 0.6236 & 1.3647 & -0.5883 & 1.2147 & 0.3269 & 0.7336 & -0.5401 \\
4 & -1.2472 & 0.4402 & 2.1573 & -0.3313 & -1.9612 & -1.6366 & 1.0801 \\
5 & 0.6236 & -0.4842 & 0.0981 & -0.3313 & -0.1307 & -0.0564 & 1.0801 \\
6 & 0.6236 & -0.7924 & -1.2748 & -1.8773 & -0.1307 & 0.7336 & -1.6202 \\
7 & 0.6236 & 1.3647 & 0.0981 & 1.2147 & -0.1307 & -0.8465 & 0.5401 \\
\hline
\end{tabular}

Computation by PCA.

Table 3 Results

\begin{tabular}{ccccccc}
\hline $\begin{array}{l}\text { Ranked by } \\
\text { components }\end{array}$ & variance & Eigenvalue & $\begin{array}{l}\text { Contribution } \\
\text { rate (\%) }\end{array}$ & $\begin{array}{l}\text { Accumulation } \\
\text { rate (\%) }\end{array}$ & $\mathrm{x}_{1}$ & $\mathrm{x}_{2}$ \\
\hline 1 & $\mathrm{X}_{5}$ & 3.3466 & 47.81 & 47.81 & 0.0033 & -0.3275 \\
2 & $\mathrm{X}_{1}$ & 1.6621 & 23.74 & 71.55 & 0.6385 & 0.5304 \\
3 & $\mathrm{X}_{4}$ & 1.4018 & 20.03 & 91.58 & -0.4599 & 0.1919 \\
4 & $\mathrm{X}_{7}$ & 0.5083 & 7.26 & 98.84 & 0.2081 & -0.4890 \\
\hline
\end{tabular}




\begin{tabular}{ccccccc}
\hline 5 & $\mathrm{X}_{6}$ & 0.0792 & 1.13 & 99.97 & 0.2039 & 0.0390 \\
6 & $\mathrm{X}_{3}$ & 0.0019 & 0.03 & 100.00 & 0.5382 & -0.2098 \\
7 & $\mathrm{X}_{2}$ & 0.0001 & 0.00 & 100.00 & -0.0792 & 0.5384 \\
\hline
\end{tabular}

Table 3 Results (continued)

\begin{tabular}{ccccc}
\hline $\mathrm{x}_{3}$ & $\mathrm{x}_{4}$ & $\mathrm{x}_{5}$ & $\mathrm{x}_{6}$ & $\mathrm{x}_{7}$ \\
\hline-0.4284 & -0.1217 & 0.4567 & 0.5158 & -0.4688 \\
-0.4104 & 0.3637 & 0.0986 & 0.0090 & 0.0203 \\
0.2606 & 0.7192 & 0.3600 & 0.1921 & -0.0001 \\
-0.0812 & 0.1011 & 0.4342 & -0.0952 & 0.7093 \\
0.2867 & -0.0422 & -0.3210 & 0.8199 & 073125 \\
0.6668 & 0.0777 & 0.2236 & -0.1169 & -0.3899 \\
0.2162 & -0.5635 & 0.5572 & 0.0450 & 0.1644 \\
\hline
\end{tabular}

Eigenvalues, Contribution Rate (\%) and Accumulation Rate (\%). Eigenvalues, contribution rate $(\%)$ and Accumulation rate $(\%)$ are shown in figure 1 and 2.

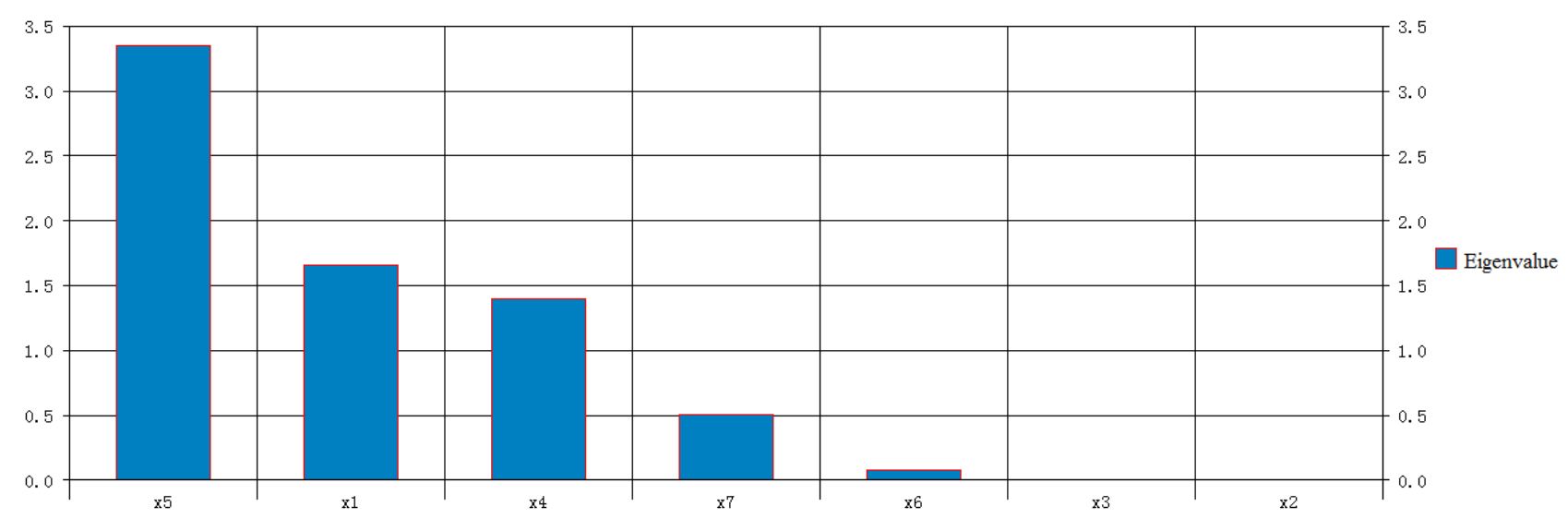

Figure 1. Eigenvalues

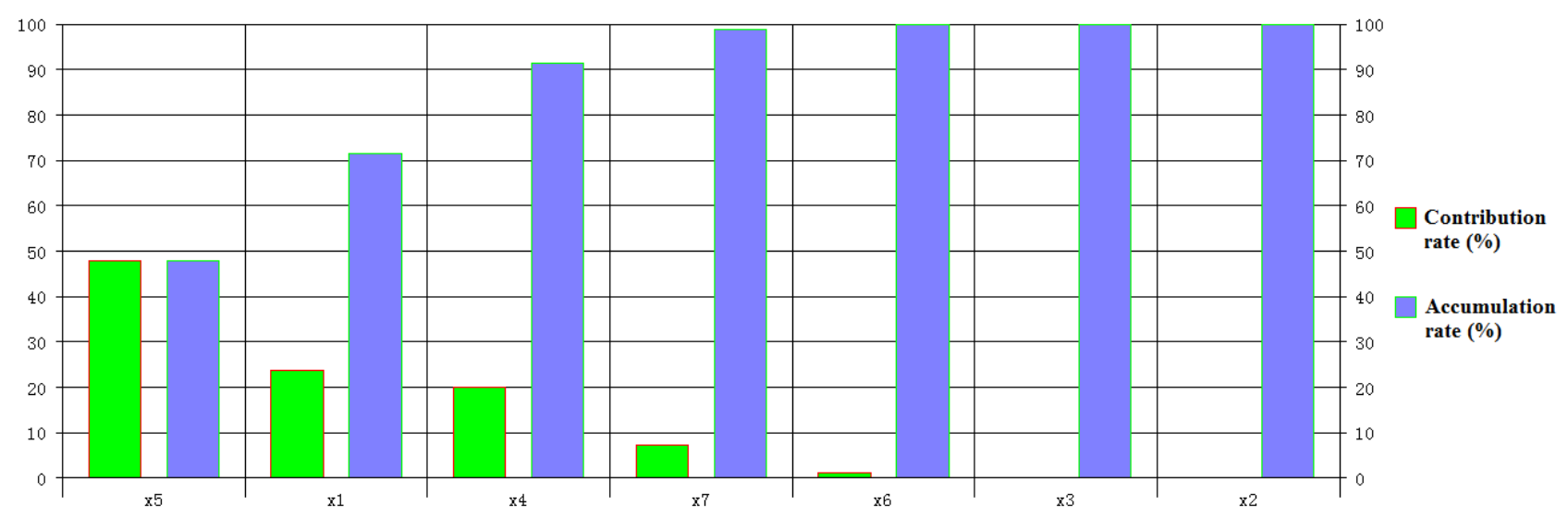

Figure 2. Contribution rate (\%) and accumulation rate (\%)

Factor Analysis While the Accumulation Rate is 90\%. Table 4 shows the factor analysis while the accumulation rate is $90 \%$. 
Table 4 Factor analysis while the accumulation rate is $90 \%$

\begin{tabular}{cccccccc}
\hline MC & NO. 1 $\left[\mathrm{x}_{5}\right]$ & $\begin{array}{c}\text { NO. 2 } \\
{\left[\mathrm{x}_{1}\right]}\end{array}$ & $\begin{array}{c}\text { NO. 3 } \\
{\left[\mathrm{x}_{4}\right]}\end{array}$ & $\begin{array}{c}\text { NO. 4 } \\
{\left[\mathrm{x}_{7}\right]}\end{array}$ & $\begin{array}{c}\text { NO. 5 } \\
{\left[\mathrm{x}_{6}\right]}\end{array}$ & $\begin{array}{c}\text { NO. 6 } \\
{\left[\mathrm{x}_{3}\right]}\end{array}$ & $\begin{array}{c}\text { NO. 7 } \\
{\left[\mathrm{x}_{2}\right]}\end{array}$ \\
\hline 1 & 1.9674 & -0.3586 & -1.2349 & 0.7765 & -0.4031 & 2.3964 & 0.1841 \\
2 & -0.4096 & 0.8122 & -0.0041 & -0.6389 & -0.5155 & 0.0228 & -0.4238 \\
3 & -1.2660 & -0.0607 & 0.0484 & 0.9524 & 0.1707 & 0.5138 & 1.4835 \\
4 & 0.5714 & -1.5180 & 1.1783 & -0.2659 & 1.8426 & -1.7206 & -1.9389 \\
5 & 0.0577 & 0.7616 & 0.8688 & -0.5733 & -0.1957 & -0.1735 & -0.4408 \\
6 & 0.8457 & 0.4733 & -1.4554 & -0.4657 & -2.0005 & -0.9568 & 1.0743 \\
7 & -1.7665 & -0.1097 & 0.5987 & 0.2149 & 1.1018 & -0.0821 & 0.0615 \\
\hline
\end{tabular}

\section{Analysis and Conclusions}

Through the above analysis of the mental health service aid of middle students, the method of principal component analysis (PCA) is significant. For example, the first principal component is $\mathrm{x}$, that is to say, when the first principal component contribution rate is $47.81 \%$, the students in reading shorthand training problems has played a major role in the process of analysis, which highlights the importance of psychological needing to learn. Other components of the analysis are similar.

The cumulative contribution rate is settled as $90 \%$. In the actual processing of middle school students' problem, this ratio can be changed according to the actual situation. If the cumulative contribution rate is $80 \%$ or $85 \%$, then the principal component is $\mathrm{x} 5, \mathrm{x} 1, \mathrm{x} 4$. If the cumulative contribution rate is $100 \%$, all the circumstances (each factor) for middle school have to be considered. The second principal components accounted for 0 , which only shows that its impact in the current state is very small. It also means that too few attentions are paid to the poor mountain children mental health education teaching activities. When things or the nature of the problem are changed with the progress of economic and social development, it may also become the primary consideration.

Middle school students' mental health assistance is a valuable consulting service for middle school students and administrators. Under different conditions, each students meeting the different situation, sometimes problems will have a significant impact on them. Middle school students' mental health assistance service is confidential, which can be free and simple. For the middle school students and the managers, mental health assistance can be of great advantage. The method of principal component analysis (PCA) used in the service of mental health assistance in middle school is also very good at the innovation and healthy development of the school and its culture.

\section{References}

[1] Xu Fulian, ZHONG Mingjie, CHEN Hai-quan, et al. Depressive syptoms and seeking psychological help among middle school students in Jiangmen [J]. China Journal of School Health, 2014, 35(10): 1500-1502.

[2] Sun Wei, NIE Ling, CHANG Chun. Depressive symptom and help-seeking status of students from a senior middle school in Beijing [J]. 2009, 30(9): 826-828.

[3] JI Juan, SHANG Zhoungming, ZHAO Qing, et al. Survey on the current situation of middle school students' psychological health in Wenchuan .County after the earthquake [J]. Sichuan Medical Science, 2013, 34(4):443-445. 
[4] Yang Ling, GONG Liangyun. Development of mental health curriculum in primary and secondary schools under psychological assistance program $[\mathrm{J}]$. Teaching and management, 2015 (30): 78-80.

[5] Shi Hongchao, Qin Jiaojiao, Wang Ziyao, et al. Construction of College Students' psychological assistance program based on Internet [J]. Higher education of coal, 2016 (4): 62-64.

[6] Zhang Runchu. Multivariate Statistical Analysis [M]. China: Science Press, 2010.

[7] Jiang Huiyuan, and Wang Wanxiang, "Application of Principal Component Analysis in Synthetic Appraisal for Multi objects Decision making," Journal of Wuhan University of Technology Transportation Science \& Engineering, March, 2004, pp. 467-470.

[8] He Xiaoqun. Multivariate Statistical Analysis (4th Edition)[M]. Beijing: Press of China People's University, 2015. 